\title{
A fuzzy model for assessing the risk exposure of procuring infrastructure mega-projects through public-private partner- ship: The case of Hong Kong-Zhuhai-Macao Bridge
}

C The Author(s) 2018. Published by Higher Education Press. This is an open access article under the CC BY license (http:// creativecommons.org/licenses/by/4.0)

\begin{abstract}
Considering the rapid urbanization growth rate particularly in developing countries, the number of infrastructure mega-projects over the past years has risen tremendously. Essentially, because infrastructure megaprojects require huge investment funds, better management skills, well qualified and experienced international expertise and technology innovation, they are mostly preferred to be procured using the PPP method compare to the use of the traditional bid-build system. In this regard, this paper aims to develop a fuzzy evaluation model for assessing the suitability of procuring infrastructure mega-projects through PPP by considering their risk exposure. The main body of Hong Kong-Zhuhai-Macao Bridge (HZMB) is used as a case project to demonstrate the practicality of the risk evaluation model. The risk evaluation model consists of four critical risk groupings, these include, construction and land risks, commercial risks, operational risks and political risks. Using the risk evaluation equation, a risk index of 4.53 out of 5.00 is computed for the selected project if it is procured through the PPP scheme. This outcome shows that the case project is not suitable for the PPP approach because its risk exposure is very high. The model developed will enable PPP practitioners to predict the likely risk exposure of procuring infrastructure megaprojects through the PPP scheme.
\end{abstract}

Keywords infrastructure mega-projects, public-private

Received October 3, 2017; accepted December 25, 2017

Albert P.C. CHAN, Robert OSEI-KYEI ( $\triangle)$

Department of Building and Real Estate, The Hong Kong Polytechnic University, Hong Kong, China

E-mail: robertoseikyei@gmail.com

Yi HU, Le YUN

Department of Construction Management and Real Estate, School of Economics and Management, Tongji University, Shanghai 200092, China partnership, Hong Kong-Zhuhai-Macao Bridge, Hong Kong, fuzzy

\section{Introduction}

Generally, infrastructure mega-projects are large scale in nature and are also characterized as very complicated (He et al., 2015). The tremendous boom in infrastructure megaprojects in recent decades comes as a result of the urgent need for infrastructure renewal and urbanization $(\mathrm{Hu}$ et al., 2016). Importantly, the cost of infrastructure mega-projects could be about $0.01 \%$ of a country's Gross Domestic Product (Hu et al., 2016). Because of the contextual sensitivity, cost and large stakeholder of infrastructure mega-projects, choosing the right procurement method is very critical. This is because a wrong approach in procuring infrastructure mega-projects may cause a lot of constraints and damage including the reputation of the stakeholders.

Globally, the public-private partnership (PPP) scheme has now become a preferred procurement approach for delivering value for money and sustainable public infrastructure (Cheung et al., 2009). Importantly, since the early 1990s, the PPP concept has spread rapidly particularly among countries in the developing regions (World Bank, 2015). The U.K, Australia, Canada and the U.S are among the countries that started to record more successful projects since PPP inception (Yescombe, 2011; Akintoye et al., 2003). It is after its success in these countries that many countries particularly those in the developing regions begun to embrace the PPP concept. Indeed, PPP is seen to be a more innovative approach in delivering public infrastructure in developing countries because it allows governments to tap into foreign private investments and international expertise (Osei-Kyei et al., 2014; Li et al., 2005). In addition, the sharing of risks and 
responsibilities among parties in PPP arrangement contributes to the reduction of the total lifecycle cost of public infrastructure (Ke et al., 2011; Xu et al., 2010). In this regard, PPP is now a preferred method by many governments particularly those in developing countries to develop sustainable and quality public infrastructure (Chan et al., 2009).

Considering the lengthy nature and cost of the bidding process in PPP arrangements, normally, small scale construction projects are not recommended for PPP (Chan et al., 2010). In essence, complex infrastructure mega-projects such as airports, seaports, bridges, tunnels and skyscrapers are more suitable for PPP method. In the case of projects in smaller scales, it is recommended that many of such projects should be bundled together and awarded as one complete PPP contract (Chan et al., 2010). Despite many successful PPP stories, over the past couple of years there have been reported failure and distress of infrastructure mega-projects, which have been procured through the PPP scheme. Such examples include the Western and Eastern Harbour Crossing (China's Hong Kong), Cross City Tunnel (Australia), Ghana National Housing Project (Ghana) and Lekki toll road concession project (Nigeria) (Osei-Kyei and Chan, 2016; Cheung and Chan, 2011a; Cheung and Chan, 2011b; Tam, 1999). Importantly, one of the major causes of the distress and failure of many megaprojects procured through PPP is the improper assessment of the suitability of these projects through the PPP scheme (Cheung and Chan, 2011a). As a matter of fact, assessing the suitability of infrastructure mega-projects through PPP is somehow subjective and fuzzy in nature and these could result in making wrongful decisions. Thus, there is the need to device a mechanism that would take into consideration the fuzziness and human bias in assessing the suitability of mega-projects through PPP. Essentially, this will enable practitioners and policy makers to evaluate the suitability of procuring infrastructure mega-projects through PPP in a more reliable and efficient manner.

Against this backdrop, this paper aims to develop a fuzzy evaluation model for assessing the risk exposure of procuring infrastructure mega-projects through PPP. Further, main body of Hong Kong-Zhuhai-Macao Bridge (HZMB) which has an estimated cost of CNY 37.4 billion is used to demonstrate the applicability of the risk evaluation model in real life situation. The outputs of this study will enable PPP practitioners and policy makers to make reliable decisions with respect to the suitability of infrastructure mega-projects through PPP schemes. To put the paper in context, the literature review on infrastructure mega-projects and risk factors in PPPs is presented first. Secondly the development of the risk evaluation model using fuzzy set theory is also presented. Thirdly, the application of the fuzzy model using the HZMB mainbody project is discussed and lastly implications and conclusions are presented.

\section{Literature review}

\subsection{Definition and characteristics of infrastructure mega-projects}

The rapid urbanization growth rate and the urgent need for infrastructure have led to a tremendous investment boom in infrastructure mega-projects globally (Hu et al., 2015). Essentially, the rapid investment growth in infrastructure mega-projects has occurred mainly in developing countries. For instance, hu et al. (2016) reported that around 203 infrastructure mega-projects have been initiated in China from 1990 to 2009 and each project reached an estimated total cost of approximately 800 million USD (5 billion CNY). In addition, there has been an increased in infrastructure mega-projects investments in other developing countries such as Brazil, Indonesia and South Africa.

Over the years, many governments and institutions have defined infrastructure mega-projects in different ways $\mathrm{(Hu}$ et al., 2015). However, in spite of the varying definitions, all infrastructure mega-projects are known to be extremely large in scope and cost (i.e. 1 billion USD) (Flyvbjerg et al., 2003). Further, infrastructure mega-projects have a large number of project participants, complex in nature and great contextual sensitivity (Hu et al., 2016; Miller and Lessard, 2000; He et al., 2015; Remington and Pollack, 2008).Considering that complexity is one of the major features of infrastructure mega-projects, he et al. (2015) classified mega-projects' complexity into six major components, including organizational complexity, technological complexity, goal complexity, cultural complexity, environmental complexity and information complexity. They further emphasized that these complexities of megaprojects often pose numerous risks of which project managers should be mindful of.

Globally, infrastructure mega-projects often face many challenges when they are been executed due to several factors. Hu et al. (2016) noted that some of the major factors inhibiting the successful performance of infrastructure mega-projects include the temporary nature of client organizations and the lack of coordination of subprojects during the execution of infrastructure megaprojects. Because client organizations are not permanent, it is difficult to ensure a proper program management of mega-projects at the organizational level (Hu et al., 2016). Mostly, the key performance indicators used to assess the performance of infrastructure mega-projects include the traditional measures of cost, time and quality (Flyvbjerg et al., 2003; Hu et al., 2016). However, recent studies including Toor and Ogunlana (2010) have mentioned that the performance of mega-projects should be assessed considering the subjective indicators such as safety, reduced conflicts and disputes, the efficient use of resources and stakeholders' satisfaction and effectiveness. Notably, infrastructure mega-projects exhibit suitable nature of projects for PPP procurement because of their 
large scale. Specifically, mega-projects involve huge investments costs and require international expertise, unique technological innovation and sophisticated management skills. In addition, the preferences for technology transfer and more local content in infrastructure mega-projects make PPP the ideal method for their procurement. However, over the years, some infrastructure mega-projects have proved not to be suitable through PPP schemes. Some projects have completely failed, whereas others are in serious distress states (Osei-Kyei and Chan, 2016). Therefore, there is a need for practitioners and policy makers to assess the appropriateness of procuring infrastructure mega-projects through PPPs by considering their risk exposure before taking decision. Apparently, the emphasis is on risk exposure because risks significantly affect investment costs. More importantly, in PPPs, value for money and better user satisfaction could only be achieved when PPP projects are not exposed too many high risks (Osei-Kyei and Chan, 2017). Therefore evaluating the risk exposure of infrastructure megaprojects provides a very strong basis for implementers to ascertain the suitability of their projects through PPP.

\subsection{Overview of research studies on risk factors in PPPs}

Risk management is a topical issue in PPP project management, in this regard, over the last couple of decades; a large strand of literature has discussed the potential risk factors in PPP projects (Ke et al., 2009). This section briefly reviews some past studies.

$\mathrm{Li}$ et al. (2005) identified 46 risk factors which affect the success of PPP projects. By means of questionnaire survey on experts, they grouped these risks into three major components. These include micro, meso and macro factors. Further, they identified construction cost overruns, construction time delay, and operational overruns as the topmost significant risk factors. Also, Thomas et al. (2003) identified eight risk factors in BOT/PPP projects by means of literature review and questionnaire survey of experts. These risk factors include traffic revenue risk, delay in land acquisition, demand risk, delay in financial closure, completion risk, cost overrun risk, debt servicing risk and direct political risks.

Further, Ameyaw and Chan (2013) also examined the risk factors in PPP water supply projects in Ghana. They mentioned that weak regulatory and monitoring regime, financing, inexperience in PPPs and public opposition are some of the common risks which policy makers and practitioners need pay attention. Similarly, Ke et al. (2011) examined the risk factors in China's PPP market. They found out that government intervention, poor political decision making, financial risk, government reliability, market demand change, corruption, subjective evaluation, interest rate, immature jurisdiction system and inflation are the top ten critical risk factors of which local practitioners and policy makers should be mindful of

In a similar study conducted by Xu et al. (2010), they grouped 17 critical risk factors in China's PPP highway projects into six broad categories. These include macroeconomic risk, construction and operation risks, government maturity risk, market environment risk, economic variability risk and government intervention. Further, they used the fuzzy set theory to evaluate the criticality of each risk grouping. They found out that government intervention is the most critical risk grouping and therefore practitioners should develop strategic mitigation plan when investing in highway PPP projects in China.

The brief review of studies shows that many researchers have attempted to explore the risk factors and have developed assessment models. However, very few, if any have focused and developed an evaluation model which could be used to calculate the likely risk exposure of procuring construction megaprojects through the PPP scheme. Thus this study aims to bridge this knowledge gap.

\section{Development of the fuzzy risk evaluation model}

\subsection{Identification of risk factors from literature}

Through a comprehensive review of germane literature, a set of 32 risk factors in PPP projects were identified. This effort formed part of a Ph.D research project that aims to develop a best practice framework for PPP implementation in Ghana drawing on experiences from Hong Kong. The set of risk factors was pretested with experts from Hong Kong and they assured the applicability and clarity of the risk factors (Osei-Kyei and Chan, 2017). Table 1 shows the set of risk factors in PPP identified from literature (OseiKyei and Chan, 2017).

\subsection{Empirical questionnaire survey}

A questionnaire survey was conducted with experienced PPP practitioners and researchers in Hong Kong. The questionnaire required experts to rate on a five-point Likert scale the probability and severity of each risk factor as applied in Hong Kong (Osei-Kyei and Chan, 2017). The experts were selected based on a two-stage sampling approach. First, two selection criteria were used to identify initial respondents. Second, the identified experts were opportunistically asked to suggest potential colleagues who may be interested to participate in this study. Most of the suggested colleagues willingly accepted to participate in the study and were therefore added to the total list of respondents (Osei-Kyei and Chan, 2017). The two selection criteria adopted were: 1) respondent should have in-depth knowledge on the general practice of PPP 


$$
\text { L }
$$




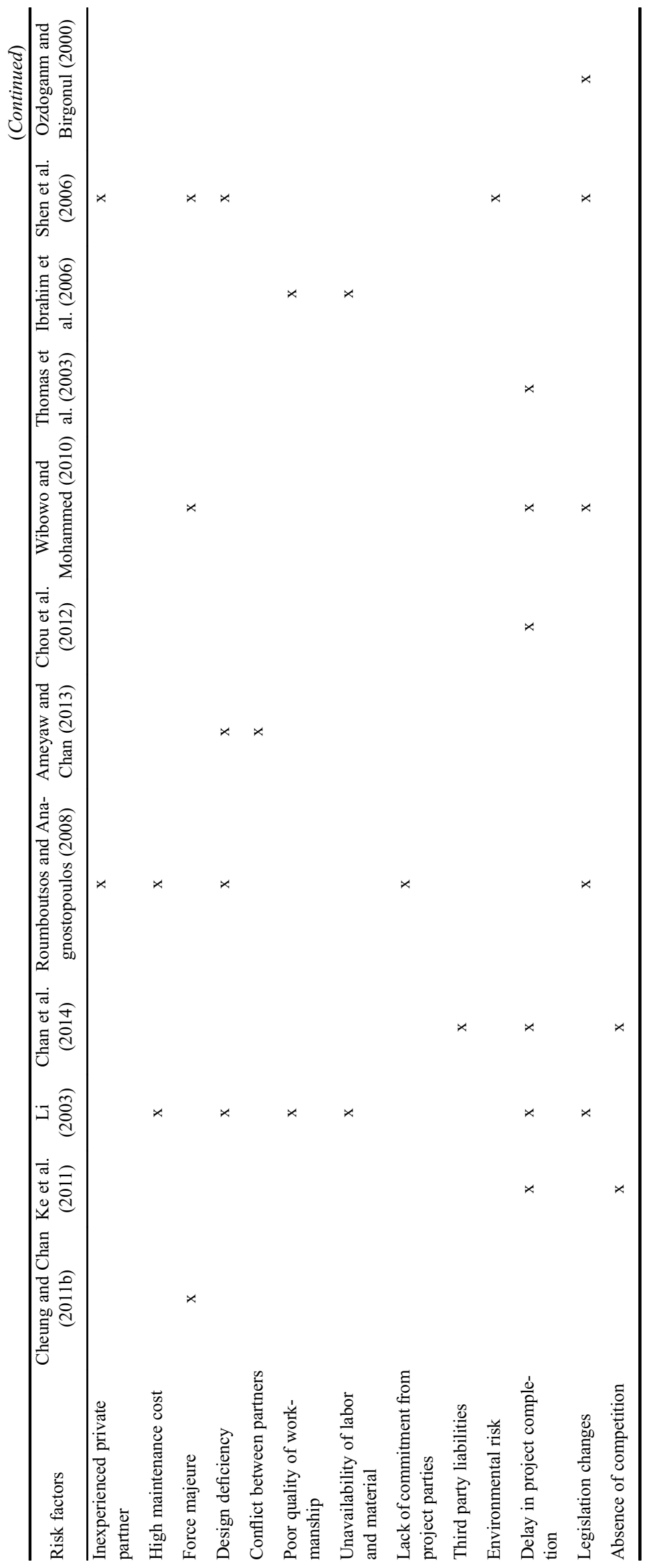


and should have followed very closely to the development of PPP in Hong Kong, and 2) respondent should have adequate direct hands-on working and/or research experience in PPP project delivery in Hong Kong (Osei-Kyei and Chan, 2017). Essentially, these criteria were deemed suitable and appropriate to enable the authors identified the required experts in the first round.

Overall, 87 experts were identified from PPP related publications in academic journals with focused on Hong Kong, dedicated private sector organization and public institutions that have expressed strong interest in PPP practice in Hong Kong (e.g. Housing department, Efficiency Unit, Architectural Service Department and Civil Engineering and Development Department). Questionnaires were sent to experts mostly by email with an option of answering through the 'Survey Monkey' online questionnaire platform. In total, 26 completed questionnaires were returned and this represents a response rate of 29.89\% (Osei-Kyei and Chan, 2017). Essentially, the low response rate is attributed to the use of online questionnaire distribution approach which always yields very low responses compared to other approaches such as face-toface (Szolnoki and Hoffmann, 2013). Notwithstanding, the sample size of 26 is considered satisfactory and reasonable when compared with previous related studies that were conducted in Hong Kong. For example, Cheung et al. (2012) and Cheung et al. (2009) obtained 34 responses, whereas Javed (2013) obtained 18 responses (Osei-Kyei and Chan, 2017). In addition, the respondents possess rich PPP experience both in research and practice, for instance, $65 \%$ of experts have more than six years of PPP experience either as researchers or practitioners (Osei-Kyei and Chan, 2017).

Moreover, $77 \%$ of the respondents are industrial practitioners who are mostly exposed to the intricacies of PPP practices compared to the academicians. These indications demonstrate that the survey responses are suitable and useful for further analysis. The details of respondents' background are presented in Osei-Kyei and Chan (2017).

3.3 Selection of critical risk factors and risk categories for PPP projects in Hong Kong

Table 2 shows the mean scores of the probability and severity of each risk factor. Further, to determine the relative significance of each risk factor, the risk impact values are calculated.

The risk impact value is determined by taking the square root of the product of probability and severity (i.e. $\sqrt{\text { probability } \times \text { severity }}$ (Chan et al., 2011). This approach of assessing the relative importance of risk factors have been used by many past studies including $\mathrm{Xu}$ et al. (2010) and Ke et al. (2010). To select the critical risk factors for further analysis, the normalization method was used (i.e. normalized value $=($ actual value - min. value $) /$ (max. value - min. value)). In this case, risk factors with normalized values equal to or greater than 0.50 are considered critical. Similarly, many studies including Ameyaw and Chan (2015) and Chan et al. (2014) have used this approach to identify critical and significant factors for further analysis.

As presented in Table 2, nine risk factors emerged as critical, these include (descending order): delay in land acquisition (CRF1), operational cost overruns (CRF2), construction cost overruns (CRF3), delay in project completion (CRF4), political interference (CRF5), unavailability of labor and materials (CRF6), change in market demand (CRF7), high financing cost (CRF8) and construction changes (CRF9).

After selecting the critical risk factors, they are further grouped into categories based on their characteristics of different aspects of PPP projects (Ameyaw and Chan, 2015). The groupings are done in order to produce a more simplified and effective evaluation model. Importantly, other statistical methods such as factor analysis could have been used for the groupings; however the sample size was insufficient to perform a satisfactory factor grouping (Ameyaw and Chan, 2015). The 9 critical risk factors were grouped into 4 unrelated categories, these include: Construction and Land Risks (CRF1, CRF3, CRF4, CRF6 and CRF9); Commercial Risks (CRF8 and CRF7); Operational Risks (CRF2) and Political Risks (CRF5). These classifications follow the grouping of risk factors in PPP projects suggested by Chan et al. (2011), Salman et al. (2007) and Wibowo and Mohamed (2010). Therefore, the categories identified are believed to be suitable and appropriate for the 9 critical risk factors.

The 4 critical risk factor groupings are used in the next stage of analysis as input variables for the fuzzy modeling.

\subsection{Application of Fuzzy Synthetic Evaluation (FSE) modeling}

Zadeh (1965) developed FSE which is a branch of fuzzy set theory. This multi-criteria decision method has been used in many different academic disciplines including health risk assessment, water quality assessment and human resource management (Liu et al., 2013; Sadiq and Rodriguez, 2004; Hsu and Yang, 1997). It is purposely used to quantify multi-evaluations and multi-attributes (Xu et al., 2010). FSE has been widely used in construction management research particularly for risk assessments (Ameyaw and Chan, 2015; Xu et al., 2010). Further other studies including $\mathrm{Hu}$ et al. (2016) have used it to develop performance index for projects. For further basic information on FSE, interested readers should refer to Liu et al. (2013), Li et al. (2013) and Xu et al. (2010).

In this study, FSE is used as the main tool to formulate a risk evaluation equation for PPP projects in Hong Kong. 
Table 2 Critical risk factors in PPP projects in Hong Kong

\begin{tabular}{|c|c|c|c|c|c|}
\hline Risk factors & Probability & Severity & Risk impact & Rank & Normalization \\
\hline Delay in land acquisition & 4.12 & 4.31 & 4.21 & 1 & 1.00 \\
\hline Operational cost overruns & 4.23 & 4.08 & 4.15 & 2 & 0.97 \\
\hline Construction cost overruns & 4.08 & 3.88 & 3.98 & 3 & 0.88 \\
\hline Delay in project completion & 3.50 & 3.58 & 3.54 & 4 & 0.65 \\
\hline Political interference & 3.42 & 3.46 & 3.44 & 5 & 0.60 \\
\hline Unavailability of labor and material & 3.46 & 3.42 & 3.44 & 6 & 0.60 \\
\hline Change in market demand & 3.35 & 3.50 & 3.42 & 7 & 0.59 \\
\hline High financing cost & 3.31 & 3.31 & 3.31 & 8 & 0.53 \\
\hline Construction changes & 3.23 & 3.35 & 3.29 & 9 & 0.52 \\
\hline Design deficiency & 3.12 & 3.35 & 3.23 & 10 & 0.49 \\
\hline Project approvals and permits delays & 3.12 & 3.23 & 3.17 & 11 & 0.46 \\
\hline Political/public opposition & 2.96 & 3.35 & 3.15 & 12 & 0.45 \\
\hline High maintenance cost & 3.19 & 3.12 & 3.15 & 13 & 0.45 \\
\hline Environmental risk & 3.08 & 3.19 & 3.13 & 14 & 0.44 \\
\hline Project operation changes & 3.00 & 3.12 & 3.06 & 15 & 0.40 \\
\hline Conflict between partners & 2.96 & 3.12 & 3.04 & 16 & 0.39 \\
\hline Lack of commitment from project parties & 2.81 & 3.19 & 2.99 & 17 & 0.36 \\
\hline Poor public decision making & 2.92 & 3.04 & 2.98 & 18 & 0.36 \\
\hline Poor quality of workmanship & 2.69 & 3.19 & 2.93 & 19 & 0.33 \\
\hline Interest rate fluctuation & 2.88 & 2.92 & 2.90 & 20 & 0.32 \\
\hline Legislation changes & 2.46 & 3.19 & 2.80 & 21 & 0.27 \\
\hline Tax regulations change & 2.50 & 2.88 & 2.69 & 22 & 0.21 \\
\hline Tariff change & 2.42 & 2.96 & 2.68 & 23 & 0.20 \\
\hline Exchange rate fluctuation & 2.58 & 2.77 & 2.67 & 24 & 0.20 \\
\hline Inflation rate fluctuation & 2.15 & 3.04 & 2.56 & 25 & 0.14 \\
\hline Force majeure & 2.27 & 2.88 & 2.56 & 26 & 0.14 \\
\hline Change in technology & 2.38 & 2.73 & 2.55 & 27 & 0.14 \\
\hline Inexperienced private partner & 2.23 & 2.73 & 2.47 & 28 & 0.09 \\
\hline Third party liabilities & 2.27 & 2.65 & 2.45 & 29 & 0.08 \\
\hline Absence of competition & 2.19 & 2.58 & 2.38 & 30 & 0.05 \\
\hline Corruption & 2.04 & 2.62 & 2.31 & 31 & 0.01 \\
\hline Changes in shareholdings of the project company & 2.31 & 2.27 & 2.29 & 32 & 0.00 \\
\hline
\end{tabular}

Although other traditional methods such as the normal weighted method could have been used, FSE provides objective weightings for the factor groupings considered in the risk evaluation equation (Hu et al., 2016). Subsequent sections show the application of the FSE in developing the risk evaluation model.

3.4.1 Calculate the appropriate weightings for Critical Risk Factors (CRFs) and Critical Risk Groupings (CRGs)

First, the weightings for the CRFs and CRGs are calculated using the mean scores obtained from the questionnaire survey. For each CRF and CRG, the weightings for both probability and severity are determined. The formula for calculating the weighting is given as (Liu et al., 2013):

$$
W_{i}=\frac{M_{i}}{\sum_{i=1}^{5} M_{i}}, 0 \leqslant W_{i} \leqslant 1, \sum W_{i}=1,
$$

where $W_{i}$ is the weighting; $M_{i}$ is the mean score of a particular criterion or factor component and $\sum W_{i}$ is the summation of mean ratings.

Using Eq. (1) the appropriate weightings for the 
CRFs and CRGs are calculated and these are shown in Table 3.

3.4.2 Determine the membership functions of Critical Risk Factors (CRFs) and Critical Risk Groupings (CRGs)

The second step in the FSE modeling is to determine the membership functions. Before deriving the membership functions, two levels are labeled for clarity and easy understanding. The first level is the CRG and the second level is the CRF. In this regard, membership functions for these two levels are derived; however, the second level membership functions are determined first, before calculating for the membership functions at the first level. The second level (i.e. CRF) membership functions are obtained from the ratings furnished by the experts given the grades for selection (i.e. $L_{1}-$ low critical to $L_{5}-$ most critical). Taking CRF1 (delay in land acquisition) as an example, the ratings for its probability are $0 \%$ as low critical, $7.7 \%$ as fairly critical, $7.7 \%$ as critical, $50.0 \%$ as very critical and $34.6 \%$ as most critical. In this regard, the membership function for probability of CRF1 is given as:

$$
\begin{aligned}
& M F_{\mathrm{CRF} 1 \text { (probability) }} \\
& \quad=\frac{0.00}{L_{1}}+\frac{0.08}{L_{2}}+\frac{0.08}{L_{3}}+\frac{0.50}{L_{4}}+\frac{0.35}{L_{5}} .
\end{aligned}
$$

This function is also expressed as $(0.00,0.08,0.08,0.50$, $0.35)$. Using the same approach, the membership function for severity of CRF1 is also determined as:

$$
\begin{aligned}
& M F_{\mathrm{CRF} 1 \text { (Severity) }} \\
& \quad=\frac{0.00}{L_{1}}+\frac{0.00}{L_{2}}+\frac{0.08}{L_{3}}+\frac{0.54}{L_{4}}+\frac{0.39}{L_{5}} .
\end{aligned}
$$

Similarly, this function is also expressed as $(0.00,0.00$, $0.08,0.54,0.39)$. Following the same approach, the membership functions for probability and severity of the remaining CRFs are derived (see Table 4 for probability and Table 5 for severity).

After determining the membership functions at the second level (i.e. CRFs), the membership functions for probability and severity at the first level can be derived. To calculate the membership functions for probability and severity of all CRGs, the following equation (Eq. (4)) is used (Xu et al., 2010):

$$
D=W_{i}^{\circ} R_{i},
$$

where $W_{i}$ is the weightings of all CRFs within each CRG and $R_{i}$ is the fuzzy evaluation matrix.

Using CRG2 as an example, the membership function

\begin{tabular}{|c|c|c|c|c|c|c|c|c|c|}
\hline$\overline{\text { No. }}$ & Risk factors & $\begin{array}{c}\text { Risk } \\
\text { probability }\end{array}$ & $\begin{array}{l}\text { Weightings } \\
\text { for each CRF }\end{array}$ & $\begin{array}{l}\text { Total MS for } \\
\text { each CRG }\end{array}$ & $\begin{array}{l}\text { Weightings } \\
\text { for each CRG }\end{array}$ & $\begin{array}{c}\text { Risk } \\
\text { severity }\end{array}$ & $\begin{array}{l}\text { Weightings } \\
\text { for each CRF }\end{array}$ & $\begin{array}{l}\text { Total MS for } \\
\text { each CRG }\end{array}$ & $\begin{array}{l}\text { Weightings } \\
\text { for each CRG }\end{array}$ \\
\hline$\overline{\mathrm{CRF} 1}$ & Delay in land acquisition & 4.12 & 0.22 & & & 4.31 & 0.23 & & \\
\hline CRF3 & Construction cost overruns & 4.08 & 0.22 & & & 3.88 & 0.21 & & \\
\hline CRF4 & Delay in project completion & 3.50 & 0.19 & & & 3.58 & 0.19 & & \\
\hline CRF6 & $\begin{array}{l}\text { Unavailability of labor and } \\
\text { materials }\end{array}$ & 3.46 & 0.19 & & & 3.42 & 0.18 & & \\
\hline CRF9 & Construction changes & 3.23 & 0.18 & & & 3.35 & 0.18 & & \\
\hline CRG1 & Construction and land risks & & & 18.39 & 0.56 & & & 18.54 & 0.56 \\
\hline CRF8 & High financing cost & 3.31 & 0.50 & & & 3.31 & 0.49 & & \\
\hline CRF7 & Change in market demand & 3.35 & 0.50 & & & 3.50 & 0.51 & & \\
\hline CRG2 & Commercial risks & & & 6.66 & 0.20 & & & 6.81 & 0.21 \\
\hline CRF2 & Operational cost overruns & 4.23 & 1.00 & & & 4.08 & 1.00 & & \\
\hline CRG3 & Operational risks & & & 4.23 & 0.13 & & & 4.08 & 0.12 \\
\hline CRF5 & Political interference & 3.42 & 1.00 & & & 3.46 & 1.00 & & \\
\hline \multirow[t]{2}{*}{ CRG4 } & Political risks & & & 3.42 & 0.10 & & & 3.46 & 0.11 \\
\hline & Total CSFG & & & 32.70 & & & & 32.89 & \\
\hline
\end{tabular}
for its probability is calculated as:

$$
\begin{aligned}
& D_{\mathrm{CRG} \text { (probability) }} \\
& \quad=(0.50,0.50) \times\left|\begin{array}{ccccc}
0.00 & 0.12 & 0.50 & 0.35 & 0.04 \\
0.00 & 0.04 & 0.62 & 0.31 & 0.04
\end{array}\right| \\
& =(0.00,0.08,0.56,0.33,0.04) .
\end{aligned}
$$

Similarly, the membership function for severity of

Table 3 Weightings of CRFs and CRGs for PPP projects in Hong Kong 
Table 4 Membership functions for risk probability of all CRFs and CRGs for PPP projects in Hong Kong

\begin{tabular}{|c|c|c|c|c|c|c|c|c|c|c|c|c|}
\hline \multirow[b]{2}{*}{$\overline{\text { CRG1 }}$} & \multirow[t]{2}{*}{ CRFs and CRGs } & \multirow[t]{2}{*}{$\begin{array}{l}\text { Weightings for } \\
\text { CRFs }\end{array}$} & \multicolumn{5}{|c|}{$\begin{array}{l}\text { Membership functions for level } 2 \\
\text { (CRFs) }\end{array}$} & \multicolumn{5}{|c|}{$\begin{array}{l}\text { Membership functions for level } 1 \\
\text { (CRGs) }\end{array}$} \\
\hline & & & & & & & & & & & & \\
\hline CRF1 & Delay in land acquisition & 0.22 & 0.00 & 0.08 & 0.08 & 0.50 & 0.35 & 0.01 & 0.07 & 0.32 & 0.43 & 0.18 \\
\hline CRF3 & Construction cost overruns & 0.22 & 0.00 & 0.04 & 0.15 & 0.50 & 0.31 & & & & & \\
\hline CRF4 & Delay in project completion & 0.19 & 0.00 & 0.08 & 0.46 & 0.35 & 0.12 & & & & & \\
\hline CRF6 & Unavailability of labor and materials & 0.19 & 0.04 & 0.04 & 0.39 & 0.50 & 0.04 & & & & & \\
\hline CRF9 & Construction changes & 0.18 & 0.00 & 0.12 & 0.58 & 0.27 & 0.04 & & & & & \\
\hline CRG2 & Commercial risks & & & & & & & & & & & \\
\hline CRF8 & High financing cost & 0.50 & 0.00 & 0.12 & 0.50 & 0.35 & 0.04 & 0.00 & 0.08 & 0.56 & 0.33 & 0.04 \\
\hline CRF7 & Change in market demand & 0.50 & 0.00 & 0.04 & 0.62 & 0.31 & 0.04 & & & & & \\
\hline CRG3 & Operational risks & & & & & & & & & & & \\
\hline CRF2 & Operational cost overruns & 1.00 & 0.00 & 0.04 & 0.08 & 0.50 & 0.39 & 0.00 & 0.04 & 0.08 & 0.50 & 0.39 \\
\hline CRG4 & Political risks & & & & & & & & & & & \\
\hline CRF5 & Political interference & 1.00 & 0.00 & 0.12 & 0.39 & 0.46 & 0.04 & 0.00 & 0.12 & 0.39 & 0.46 & 0.04 \\
\hline
\end{tabular}

Table 5 Membership functions for risk severity of all CRFs and CRGs for PPP projects in Hong Kong

\begin{tabular}{|c|c|c|c|c|c|c|c|c|c|c|c|c|}
\hline$\overline{\text { CRG1 }}$ & \multirow[t]{2}{*}{ CRFs and CRGs } & $\begin{array}{l}\text { Weightings for } \\
\text { CRFs }\end{array}$ & \multicolumn{5}{|c|}{$\begin{array}{l}\text { Membership functions for level } 2 \\
\text { (CRFs) }\end{array}$} & \multicolumn{5}{|c|}{$\begin{array}{l}\text { Membership functions for level } 1 \\
\text { (CRGs) }\end{array}$} \\
\hline & & & & & & & & & & & & \\
\hline CRF1 & Delay in land acquisition & 0.23 & 0.00 & 0.00 & 0.08 & 0.54 & 0.39 & 0.00 & 0.07 & 0.30 & 0.43 & 0.19 \\
\hline CRF3 & Construction cost overruns & 0.21 & 0.00 & 0.04 & 0.35 & 0.31 & 0.31 & & & & & \\
\hline CRF4 & Delay in project completion & 0.19 & 0.00 & 0.08 & 0.35 & 0.50 & 0.08 & & & & & \\
\hline CRF6 & Unavailability of labor and materials & 0.18 & 0.00 & 0.12 & 0.46 & 0.31 & 0.12 & & & & & \\
\hline CRF9 & Construction changes & 0.18 & 0.00 & 0.15 & 0.35 & 0.50 & 0.00 & & & & & \\
\hline CRG2 & Commercial risks & & & & & & & & & & & \\
\hline CRF8 & High financing cost & 0.49 & 0.00 & 0.08 & 0.54 & 0.39 & 0.00 & 0.02 & 0.08 & 0.42 & 0.45 & 0.04 \\
\hline CRF7 & Change in market demand & 0.51 & 0.04 & 0.08 & 0.31 & 0.50 & 0.08 & & & & & \\
\hline CRG3 & Operational risks & & & & & & & & & & & \\
\hline CRF2 & Operational cost overruns & 1.00 & 0.00 & 0.04 & 0.19 & 0.42 & 0.35 & 0.00 & 0.04 & 0.19 & 0.42 & 0.35 \\
\hline CRG4 & Political risks & & & & & & & & & & & \\
\hline CRF5 & Political interference & 1.00 & 0.00 & 0.12 & 0.39 & 0.42 & 0.08 & 0.00 & 0.12 & 0.39 & 0.42 & 0.08 \\
\hline
\end{tabular}

CRG2 is also calculated as:

$$
\begin{aligned}
& D_{\mathrm{CRG} 2 \text { (severity) }} \\
& \quad=(0.49,0.51) \times\left|\begin{array}{ccccc}
0.00 & 0.08 & 0.54 & 0.39 & 0.00 \\
0.04 & 0.08 & 0.31 & 0.50 & 0.08
\end{array}\right| \\
& =(0.02,0.08,0.42,0.45,0.04) .
\end{aligned}
$$

Following the same approach, the membership functions for probability and severity of all CRGs are calculated (see Table 4 for probability and Table 5 for severity).

After computing for the membership functions of all CRGs, the risk evaluation index for each $\mathrm{CRG}$ is determined. This will enable the development of the overall risk evaluation index for PPP projects in Hong Kong. However, to determine the risk evaluation index for each CRG, the indices for probability and severity of each CRG has to be determined first. The following equation (Eq. (5)) is used to determine the indices for probability and severity of CRGs, (Ameyaw and Chan, 2015):

$$
\text { Risk Evaluation Index }=\sum_{i=1}^{5} D \times L,
$$

where, $L$ is the set of grade alternatives (i.e. $1-$ low critical and 5-most critical).

Using CRG1 as an example, the index for its probability 
is calculated as:

CRG1 risk index $($ probability)

$$
=(0.01,0.07,0.32,0.43,0.18) \times(1,2,3,4,5)=3.73 .
$$

In a similar manner, the severity of $\mathrm{CRG} 2$ is also calculated as:

$$
\begin{aligned}
& \text { CRG1 risk index }_{(\text {severity })} \\
& \quad=(0.01,0.07,0.30,0.43,0.19) \times(1,2,3,4,5)=3.71 .
\end{aligned}
$$

Following this approach, the indices for probability and severity for each CRG are calculated and these are shown in Table 6.

After calculating for the risk indices for probability and severity for each CRG, the risk evaluation index for each CRG is calculated by taking the square root of the product of probability and severity (i.e. $\sqrt{\text { probability } \times \text { severity) }}$. Table 7 (5th column) shows the risk evaluation index for each CRG.

3.5 Developing overall risk evaluation model for PPP projects

To develop the risk evaluation equation for PPP projects in Hong Kong, a linear and additive model is used. This implies that the indices of all CRGs are used to formulate a linear and additive model. A linear model is adopted because it allows different scale of measurement for the CRFs to be used in the risk evaluation equation. Nonetheless, previous studies including Yeung et al. (2009) used a linear and additive model to formulate a partnering performance index. Therefore, using a linear to express the risk evaluation model was also considered suitable and logical.
Before, expressing the risk evaluation model in a linear equation form, the risk evaluation index derived through FSE for each CRG (see Table 7, 5th column) was further normalized so that they sum up to one. Table 7, column 6 shows the normalized risk index for each CRG.

After normalizing the risk index for all CRGs, the risk evaluation model is expressed using the following equation:

Risk Evaluation Index for PPP projects

$$
\begin{aligned}
= & (0.25 \times \text { construction and land risks }) \\
& +(0.23 \times \text { commercial risks }) \\
& +(0.28 \times \text { operational risks }) \\
& +(0.24 \times \text { political risks }) .
\end{aligned}
$$

The evaluation model presented in Eq. (6) makes it possible for practitioners to reliably and objectively evaluate the risk exposure of procuring infrastructure mega-projects through PPP schemes before their implementation. As presented in the model, operational risk has the highest coefficient of 0.28 , followed by construction and land risks (0.25), political risks (0.24) and lastly, commercial risks $(0.23)$. These outputs suggests that operational risks as well as construction and land risks are very critical in Hong Kong's PPP market and therefore practitioners should adopted proper mitigation measures for PPP projects at the operational stage.

Subsequent section demonstrates how the risk evalua-

\begin{tabular}{|c|c|c|c|c|c|c|c|c|c|c|c|c|c|}
\hline \multirow{2}{*}{ No. } & \multirow{2}{*}{ CRGs } & \multicolumn{6}{|c|}{ Probability } & \multicolumn{6}{|c|}{ Severity } \\
\hline & & 1 & 2 & 3 & 4 & 5 & Index & 1 & 2 & 3 & 4 & 5 & Index \\
\hline$\overline{\mathrm{CRG} 1}$ & Construction and land risks & 0.01 & 0.07 & 0.32 & 0.43 & 0.18 & 3.73 & 0.00 & 0.07 & 0.30 & 0.43 & 0.19 & 3.71 \\
\hline CRG2 & Commercial risks & 0.00 & 0.08 & 0.56 & 0.33 & 0.04 & 3.36 & 0.02 & 0.08 & 0.42 & 0.45 & 0.04 & 3.44 \\
\hline CRG3 & Operational risks & 0.00 & 0.04 & 0.08 & 0.50 & 0.39 & 4.27 & 0.00 & 0.04 & 0.19 & 0.42 & 0.35 & 4.08 \\
\hline CRG4 & Political risks & 0.00 & 0.12 & 0.39 & 0.46 & 0.04 & 3.45 & 0.00 & 0.12 & 0.39 & 0.42 & 0.08 & 3.49 \\
\hline
\end{tabular}
tion model (i.e. Eq. (6)) could be applied in real-life situation using a construction megaproject (ie, the Hong Kong-Zhuhai-Macao Bridge (HZMB)). This will enhance local practitioners understanding on the utilization of this risk evaluation model.

Table 6 Probability and severity indices of all CRGs for PPP projects in Hong Kong

Table 7 Risk evaluation index of each CRG for PPP projects in Hong Kong

\begin{tabular}{lccccc}
\hline No. & CRGs for PPP projects & Probability & Severity & Risk evaluation index & Coefficient* \\
\hline CRG1 & Construction and land risks & 3.73 & 3.71 & 3.72 & 0.25 \\
CRG2 & Commercial risks & 3.36 & 3.44 & 3.40 & 0.23 \\
CRG3 & Operational risks & 4.27 & 4.08 & 4.17 & 0.28 \\
CRG4 & Political risks & 3.45 & 3.49 & 3.47 & 0.24 \\
\hline
\end{tabular}

Note: ${ }^{*}$ Coefficient $=($ Risk evaluation index of CRG $/ \Sigma$ Risk evaluation index of all CRGs $)$ 


\section{Assessing the risk exposure of procuring the case project through PPP}

This section demonstrates the application of the risk evaluation model by calculating the risk index of HZMB's main-body project when procured through the PPP scheme. Importantly, local practitioners will be informed of how the risk evaluation model could be applied in reallife situation.

\subsection{Brief background of the HZMB}

The HZMB is a mega-project which was first proposed in the early 1980s by Mr. Wu of the Hopewell Holdings Limited (Cheung and Chan, 2011a). It is a $55 \mathrm{~km}$ dual three-lane carriageway which will span across three regions, Hong Kong, Zhuhai and Macao. The aim of this extensive road network is to foster trade and infrastructure network among the three regions. More importantly, it was projected that the HZMB project will improve the competitiveness of the Perl River Delta Region (Cheung and Chan, 2009).

The approved budget of the project is around CNY 38.01 billion. The HZMB which is currently under construction was initially proposed to be procured through the PPP scheme. Essentially, the idea of using the PPP approach was proposed in 2002, unfortunately, this original idea was dramatically reverted by the three governments in 2008 (Cheung and Chan, 2009). In the latter part of 2008, it was officially announced that the traditional procurement was the proposed method that will be used for procuring the main body of HZMB. The main body includes the eastern and western artificial islands and a $29.6-\mathrm{km}$ bridge and tunnel connecting the Zhuhai city and the two artificial islands. This clearly implied that the three governments will now be fully responsible for the funding of the proposed project. The residual sections of HZMB would be implemented through the Hong Kong, Macao, and Guangdong provincial governments, respectively.

Under the new procurement arrangement for the HZMB's main body, the proposed contribution from the Hong Kong government was CNY 6.75 billion, CNY 7 billion from the Guangzhou - Central government and 1.98 billion CNY from the Macao government (Cheung and
Chan, 2009). Because the total contribution from the three governments amounts to 15.73 billion CNY, the remaining cost was proposed to be funded through bank loans (Cheung and Chan, 2011a).

Though over the years, many explanations have been given by commentators and some researchers concerning the decision by the three governments to rescind the use of PPP, there has not been critical assessment of the suitability of using PPP for the case project particularly on its risk exposure. Importantly, an evaluation of the risk exposure of procuring the case project through PPP will provide much in-depth understanding and appreciation of the decision taken by the three governments. Therefore, there is an urgent need to assess the risk exposure of procuring the case project through the PPP method. Given that the PPP risk index tool used was developed based on the Hong Kong experience and most PPP practical knowledge in the region heavily rely on the Western and Eastern Harbour Crossing project (Chan and Cheung, 2013), whose project characteristics and requirements are very close to that of the HZMB's main body, the PPP risk index aforementioned has an application potential for the selected case.

\subsection{Risk evaluation index of the case project}

To determine the risk index of the case project, an empirical questionnaire survey was conducted with PPP experts with adequate experience in PPP and in-depth knowledge on the case project. In total, 11 experts from the academic and/or industrial sectors were invited to evaluate the probability and severity of the risk factors presented in the evaluation model on a five point Likert scale. Questionnaires were sent by emails to respondents and after sending series of reminders within the two-week period, five valid responses were received. Table 8 shows the background of respondents. As presented in the table, the experts possess rich and adequate experience in PPP; therefore they were of good standing to provide very reliable responses on the risk exposure of the case project through PPP.

Table 9 shows the results of the expert survey. The risk impact for each of the risk category in the evaluation model is calculated by taking the average of the total risk impact score. Using Construction and Land Risks (CRG1) as an example, its risk impact score is calculated as:

Table 8 Background of experts

\begin{tabular}{lcccc}
\hline ID & Position & Institution & Sector & Years of PPP experience \\
\hline EXP1 & Lecturer & Local university & Academic & $11-15$ years \\
EXP2 & Civil engineer & Local construction/Consultancy firm & Private/Public & $11-15$ years \\
EXP3 & Civil engineer & Local construction firm & Private & $11-15$ years \\
EXP4 & Assistant professor & Local university & Academic & $6-10$ years \\
EXP5 & Associate professor & Local university & Academic & $16-20$ years \\
\hline
\end{tabular}


Table 9 Average risk impact score for each CRG

\begin{tabular}{|c|c|c|c|c|c|c|}
\hline No. & Risk factors & Probability & Severity & Risk impact score & Risk impact of CRG & Total risk impact score \\
\hline$\overline{\mathrm{CRF} 1}$ & Delay in land acquisition & 4.20 & 4.00 & 4.10 & & \\
\hline CRF3 & Construction cost overruns & 4.80 & 4.40 & 4.60 & & \\
\hline CRF4 & Delay in project completion & 4.25 & 4.80 & 4.52 & & \\
\hline CRF6 & Unavailability of labor and materials & 4.00 & 4.40 & 4.20 & & \\
\hline CRF9 & Construction changes & 4.20 & 4.50 & 4.35 & & \\
\hline CRG1 & Construction and land risks & & & & 4.35 & 21.77 \\
\hline CRF8 & High financing cost & 4.54 & 4.00 & 4.26 & & \\
\hline CRF7 & Change in market demand & 4.20 & 4.00 & 4.10 & & \\
\hline CRG2 & Commercial risks & & & & 4.18 & 8.36 \\
\hline CRF2 & Operational cost overruns & 4.40 & 4.90 & 4.64 & & \\
\hline CRG3 & Operational risks & & & & 4.64 & 4.64 \\
\hline CRF5 & Political interference & 4.87 & 5.00 & 4.93 & & \\
\hline CRG4 & Political risks & & & & 4.93 & 4.93 \\
\hline
\end{tabular}

$$
\frac{4.10(\mathrm{CRF} 1)+4.60(\mathrm{CRF} 3)+4.52(\mathrm{CRF} 4)+4.20(\mathrm{CRF} 6)+4.35(\mathrm{CRF} 9)}{5}=4.35 .
$$

Following the same approach, the risk impact scores for the remaining CRGs are determined (see Table 9).

After calculating the relative impact of each CRG, the risk index for the case project is calculated as follows:

Risk Evaluation Index of the case project

$$
\begin{aligned}
= & (0.25 \times 4.35)+(0.23 \times 4.18)+(0.28 \times 4.64) \\
& +(0.24 \times 4.93)=4.53 .
\end{aligned}
$$

Using the fuzzy risk evaluation model, the risk index of the HZMB if procured through the PPP scheme is 4.53 out of 5.00, which implies that its risk exposure is 'very high.' This output supports the findings of Cheung and Chan (2011a), where the negative factors of the case project outweigh the positive factors when it is procured through the PPP scheme. Therefore, the conclusion drawn from their analysis was that the case project is not suitable for PPP. Similarly, the risk index of 4.53 (very high) clearly suggests that PPP is not the appropriate procurement method for the case project. Apparently, this suggestion is also in line with the decision made by the three host governments.

It is hoped that practitioners will use the fuzzy risk evaluation model to assess the likely risk exposure of infrastructure mega-projects when they are procured through PPPs before taking final decision.

\section{Implications for practice}

The outputs of this study offer several management implications for practice and research. First, it provides a reliable tool which could be used by practitioners to predict the likely risk exposure of procuring infrastructure megaprojects through the PPP scheme. Essentially, this will enable them to confidently ascertain the suitability of their projects through PPP. Second the findings inform local practitioners of the critical risk factors which affect the success of PPP projects in Hong Kong. This will also help them to devise mitigation plans prior to the implementation of their projects if they decide to choose the PPP route. Lastly, the fuzzy risk evaluation model could be adopted for further empirical studies in jurisdictions with characteristics and features of PPP that are similar to Hong Kong.

\section{Conclusions}

This paper has developed a fuzzy risk evaluation model which could be used to assess the risk exposure of infrastructure mega-projects. The HZMB's main-body project which is a mega-project is used to demonstrate how the model could be used in real life situation. The risk evaluation model consists of four critical risk groupings; these include construction and land risks, commercial risks, operational risks and political risks. Among the critical risk groupings, operational risk has the highest coefficient of 0.28 , followed by construction and land risks $(0.25)$, political risks $(0.24)$ and commercial risks $(0.23)$. The case project was used to demonstrate the feasibility of the model. Using the risk evaluation equation, a risk index of 4.53 is achieved for the case project if it is procured 
through the PPP scheme. This suggests that the risk exposure of the case project is very high if it is procured through the PPP scheme. This output supports the actual decision made by the host governments and other previous studies such as Cheung and Chan (2011a). Therefore, it is strongly suggested that the PPP method is not the appropriate procurement route for the case project.

Essentially, the outputs of this study inform local practitioners of the potential risk factors that affect PPP projects success in Hong Kong. This will enable practitioners to develop strategic mechanisms before engaging in PPP projects. Further, the fuzzy risk evaluation model has made it possible for local practitioners to predict the likely risk exposure of procuring infrastructure mega-projects through the PPP scheme. Apparently this will enable them to make good decision as to the suitability of infrastructure mega-projects through PPP.

Acknowledgements This paper forms part of a Ph.D research project entitled "A best practice framework for PPP implementation for infrastructure development in Ghana" from which other papers have been produced with different objective/scope but sharing the same background and methodology. The research project described is fully supported by the Hong Kong Ph.D Fellowship Scheme from the Research Grants Council (RGC) of the Hong Kong Special Administrative Region and The Hong Kong Polytechnic University, Hong Kong. Authors wish to express their sincere gratitude to all PPP practitioners and researchers in Hong Kong who participated in this research study.

\section{Reference}

Akintoye A, Hardcastle C, Beck M, Chinyio E, Asenova D (2003). Achieving best value in private finance initiative project procurement. Construction Management and Economics, 21(5): 461-470

Ameyaw E E, Chan A P C (2013). Identifying public-private partnership (PPP) risks in managing water supply projects in Ghana. Journal of Facilities Management, 11(2): 152-182

Ameyaw E E, Chan A P C (2015). Evaluation and ranking of risk factors in public-private partnership water supply projects in developing countries using fuzzy synthetic evaluation approach. Expert Systems with Applications, 42(12): 5102-5116

Chan A P, Lam P T, Chan D W, Cheung E, Ke Y (2010). Potential obstacles to successful implementation of public-private partnerships in Beijing and the Hong Kong Special Administrative Region. Journal of Management Engineering, 26(1): 30-40

Chan A P, Lam P T, Wen Y, Ameyaw E E, Wang S, Ke Y (2014). Crosssectional analysis of critical risk factors for PPP water projects in China. Journal of Infrastructure Systems, 21(1): 04014031

Chan A P C, Cheung E, (2013). Public Private Partnerships in International Construction: Learning from Case Studies. Hoboken: Routledge

Chan A P C, Lam P T, Chan D W, Cheung E, Ke Y (2009). Drivers for adopting public private partnerships. Journal of Construction Engineering and Management, 135(11): 1115-1124

Chan A P C, Yeung J F, Yu C C P, Wang S Q, Ke Y (2011). Empirical study of risk assessment and allocation of public-private partnership projects in China. Journal of Management Engineering, 27(3): 136148

Cheung E, Chan A P C (2011a). Evaluation model for assessing the suitability of public-private partnership projects. Journal of Management Engineering, 27(2): 80-89

Cheung E, Chan A P C (2011b). Risk factors of public-private partnership projects in China: Comparison between the water, power, and transportation Sectors. Journal of Urban Planning and Development, 137(4): 409-415

Cheung E, Chan A P C (2009). Is BOT the best financing model to procure infrastructure projects? A case study of the Hong KongZhuhai-Macao Bridge. Journal of Property Investment \& Finance, 27 (3): 290-302

Cheung E, Chan A P C, Kajewski S (2009). Enhancing value for money in public private partnership projects. Journal of Financial Management of Property and Construction, 14(1): 7-20

Cheung E, Chan A P C, Kajewski S (2012). Factors contributing to successful public private partnership projects. Journal of Facilities Management, 10(1): 45-58

Chou J S, Tserng H P, Lin C, Yeh C P (2012). Critical factors and risk allocation for PPP policy: Comparison between HSR and general infrastructure projects. Transport Policy, 22: 36-48

Flyvbjerg B, Bruzelius N, Rothengatter W (2003). Megaprojects and risk: An anatomy of ambition. Cambridge: Cambridge University Press

He Q, Luo L, Hu Y, Chan A P (2015). Measuring the complexity of mega construction projects in China-A fuzzy analytic network process analysis. International Journal of Project Management, 33(3): $549-563$

Hsu T H, Yang T S (1997). The application of fuzzy synthetic decision to the human resource management. Fu Jen Management Reviews, 4 (2): $85-100$

Hu Y, Chan A P, Le Y, Jin R Z (2015). From construction megaproject management to complex project management: Bibliographic analysis. Journal of Management Engineering, 31(4): 04014052

Hu Y, Chan A P, Le Y, Xu Y, Shan M (2016). Developing a program organization performance index for delivering construction megaprojects in China: Fuzzy synthetic evaluation analysis. Journal of Management Engineering, 32(4): 05016007

Ibrahim A D, Price A D F, Dainty A R J (2006). The analysis and allocation of risks in public-private partnerships in infrastructure projects in Nigeria. Journal of Financial Management of Property and Construction, 11(3): 149-164

Javed A A (2013). A model of output specifications for public-private partnership projects. Dissertation for the Doctoral Degree. Hong Kong: The Hong Kong Polytechnic University

Ke Y, Wang S, Chan A P, Cheung E (2009). Research trend of publicprivate partnership in construction journals. Journal of Construction Engineering and Management, 135(10): 1076-1086

Ke Y, Wang S, Chan A P, Cheung E (2011). Understanding the risks in China's PPP projects: Ranking of their probability and consequence. Engineering, Construction, and Architectural Management, 18(5): 481-496

Ke Y, Wang S, Chan A P, Lam P T (2010). Preferred risk allocation in China's public-private partnership (PPP) projects. International Journal of Project Management, 28(5): 482-492 
Li B (2003). Risk Management of Construction Public Private Partnership Projects. Dissertation for the Doctoral Degree. Glasgow: Glasgow Caledonian University

Li B, Akintoye A, Edwards P J, Hardcastle C (2005). The allocation of risk in PPP/PFI construction projects in the UK. International Journal of Project Management, 23(1): 25-35

Li T H, Ng S T, Skitmore M (2013). Evaluating stakeholder satisfaction during public participation in major infrastructure and construction projects: A fuzzy approach. Automation in Construction, 29: 123135

Liu J, Li Q, Wang Y (2013). Risk analysis in ultra-deep scientific drilling project-A fuzzy synthetic evaluation approach. International Journal of Project Management, 31(3): 449-458

Miller R, Lessard D (2000). The Strategic Management of Large Engineering Projects: Shaping Institutions, Risks and Governance. Boston: MIT Press

Osei-Kyei R, Chan A P C (2016). Developing transport infrastructure in Sub-Saharan Africa through public-private partnerships: Policy practice and implications. Transport Reviews, 36(2): 170-186

Osei-Kyei R, Chan A P C (2017). Risk assessment in public-private partnership infrastructure projects. Construction Innovation, 17(2): 204-223

Osei-Kyei R, Dansoh A, Ofori-Kuragu J K (2014). Reasons for adopting Public-Private Partnership (PPP) for construction projects in Ghana. International Journal of Construction Management, 14(4): 227-238

Ozdoganm I D, Birgonul M T (2000). A decision support framework for project sponsors in the planning stage of build-operate-transfer (BOT) projects. Construction Management and Economics, 18(3): 343-353

Remington K, Pollack J (2008). Tools for Complex Projects. Aldershot: Routledge

Roumboutsos A, Anagnostopoulos K P (2008). Public-private partnership projects in Greece: Risk ranking and preferred risk allocation. Construction Management and Economics, 26(7): 751-763

Sadiq R, Rodriguez M J (2004). Fuzzy synthetic evaluation of disinfection by-products - a risk-based indexing system. Journal of
Environmental Management, 73(1): 1-13

Salman A F, Skibniewski M J, Basha I (2007). BOT viability model for large-scale infrastructure projects. Journal of Construction Engineering and Management, 133(1): 50-63

Shen L Y, Platten A, Deng X P (2006). Role of public private partnerships to manage risks in public sector projects in Hong Kong. International Journal of Project Management, 24(7): 587-594

Szolnoki G, Hoffmann D (2013). Online, face-to-face and telephone surveys - Comparing different sampling methods in wine consumer research. Wine Economics and Policy, 2(2): 57-66

Tam C M (1999). Build-operate-transfer model for infrastructure developments in Asia: Reasons for successes and failures. International Journal of Project Management, 17(6): 377-382

Thomas A V, Kalidindi S N, Ananthanarayanan K (2003). Risk perception analysis of BOT road project participants in India. Construction Management and Economics, 21(4): 393-407

Toor R S, Ogunlana S O (2010). Beyond the 'iron triangle': Stakeholder perception of key performance indicators (KPIs) for large-scale public sector development projects. International Journal of Project Management, 28(3): 228-236

Wibowo A, Mohamed S (2010). Risk criticality and allocation in privatised water supply projects in Indonesia. International Journal of Project Management, 28(5): 504-513

World Bank (2015). Private Participation in Infrastructure (PPI). http:// ppi.worldbank.org/explore/ppi_exploreRegion.aspx?regionID $=1$, 2015-5

Xu Y, Yeung J F, Chan A P C, Chan D W, Wang S Q, Ke Y (2010). Developing a risk assessment model for PPP projects in China-A fuzzy synthetic evaluation approach. Automation in Construction, 19 (7): 929-943

Yescombe E R (2011). Public-Private Partnerships Principles of Policy and Finance. Oxford: Elsevier

Yeung J F, Chan A P, Chan D W (2009). Developing a performance index for relationship-based construction projects in Australia: Delphi study. Journal of Management Engineering, 25(2): 59-68

Zadeh L A (1965). Fuzzy sets. Information and Control, 8(3): 338353 